\title{
Osteoid osteoma like unusual cause of cervico-brachialgia
}

\author{
Martiniani M*, Meco L, Procaccini R, Giampaolini and Specchia N \\ Clinic of Orthopaedics, Politecnic University of Ancona, Italy
}

\begin{abstract}
Objective: The aim of this study was to describe a case in which an unusual osteoid osteoma was located into the articular process of C6.

Summary of background data: Osteoid osteoma is a small, benign, osteoblastic skeletal neoplasm that constitutes up $10 \%$ of all benign bone tumors of the spine, observed in patients younger than 30 years of age with a resistant localized neck pain, especially at night, that is noticeably relieved taking acetylsalicylic acid. In the cervical spine the injury is frequently located in the immediate vicinity of vertebral artery, of the spinal cord, and/or the nerve roots so this often renders its excision difficult and risky.

Methods.: A 20 years-old man presented us with a severe pain in the cervical and reported a history of worsening cervicobrachialgia with the emphasis on night and a significant benefit after taking acetylsalicylic acid.

Results: MRI with T1 weighting showed a diffuse hypointensity signal area in the right joint process of C6 and a focal high signal area on T2 weighting images. The X-ray examination and CT examination clearly showed a oval lesion surrounded by an area of sclerosis on the right articular process of C6 which formed the medial wall of the right vertebral artery foramen. The three-phase [Tc-99] MDP bone scan was positive. After Radiological studies we made diagnosis of osteoid osteoma of the right articular process of $\mathrm{C} 6$ and decided for surgical excision of the lesion.
\end{abstract}

Conclusion: The osteoid osteoma of the cervical spine should be suspected in any young patient with cervicobrachial or neck pain especially if the pain gets worse at night and surgical treatment is the definitive treatment and complete excision of the tumor leads to a rapid and permanent improvement of pain symptoms.

\section{Introduction}

Osteoid osteomas is a benign bone tumors that rarely settle in the cervical spine [1-4], that was first described by Jaffe in 1935 [5], and afterward Linctenstein [6] independently defined benign osteoblastoma as a different entity in 1956.

The osteoid osteoma is a small benign tumor osteoblastic; the term nidus, which was described as the "core" or "nidus-like focus" by Jaffe, refers to the tumor itself and is composed of bone at various stages of maturity within a highly vascular connective tissue stroma surroundend by sclerotic bone. The centre of the nidus usually is the most hightly mineralized part, displaying various amounts of mineralization [5]

The vast majority of these tumors are observed in patients younger than 30 years of age. Over two-thirds of cases occur in men and boys between 5 and 25 years of age and the most important symptom in patients with osteoid osteoma is a resistant localized neck pain and stiffness in the spine.

The pain is initially uncertain but progressively becomes constant and strong in nature, is worse at rest, especially at night, and is noticeably relieved by nonsteroidal anti-inflammatory drugs (NSAIDs) $[7,8]$.

Osteoid osteoma constitutes approximately $10 \%$ of all primary benign bone tumors and make up $10 \%$ of all benign bone tumors of the spine $[9,10]$.

It is localized in the cervical spine in $4 \%$ of cases, representing $40 \%$ of the cases affecting the vertebral column.one third of which are located in the cervical spine [11]. When it involves the spine, it is usually located in the posterior elements or in the posterior part of the body and extends into the posterior element [12].
In the cervical spine the injury is frequently located in the immediate vicinity of vertebral artery [13] of the spinal cord, and/ or the nerve roots so this often renders its excision difficult and risky through an mini-invasive approach [14].

Percutaneous radiofrequency coagulation (PRC) has shown to be effective in the treatment of OO of the hip and limbs [15-17] , but its role in the treatment of vertebral and above all cervical localizations is still unclear, because of the limited number of cases reported and coagulation in the vicinity of nervous and vascular structures is risky [18]. For this reason, the complete excision through a minimally invasive approach is often difficult and percutaneous radiofrequency ablation does not have a clearly defined role because of the risks associated with hyperthermia. Special attention must be given to complete removal of the tumor during the surgical approach.

We report a case in which an unusual osteoid osteoma was located into the articular process of C6.

\section{Case report}

A 20 years-old man presented us with a severe pain in the cervical region. The patient reported a history of worsening cervicobrachialgia

Correspondence to: Monia Martiniani, MD, Clinic of Orthopaedics, Politecnic University of Ancona, 60100 Ancona, Italy, Tel: 00393332543078; Fax: 00390715963628; E-mail: monamartin@tiscali.it

Key words: osteoid osteoma, cervical spine, bone tumors, neck pain

Received: December 04, 2017; Accepted: December 27, 2017; Published: December 30, 2017 
for about a year with the emphasis on night of neck pain and a significant benefit after taking acetylsalicylic acid. There was no history of injury.

The clinical examination was essentially negative, in particular neurological examination was unremarkable with normal muscle strength and no evidence of myelopatic signs. The laboratory finding were normal while the $\mathrm{X}$-ray examination showed an expansive lesion at the articular process of sixth cervical vertebra surrounded by sclerosis (Figure 1-3). The three-phase [Tc-99] MDP bone scan was positive with an increased uptake at the lower cervical region. After Radiological studies we made diagnosis of osteoid osteoma of the right articular process of C6 and decided for surgical excision of the lesion.

The patient had previously performed a selective arteriography of the right and left vertebral artery, which showed the presence of neoformed vessels with intense and persistent vascular flow of the lesion originated from an ectasic root of the right vertebral artery, commencing in the C5-C6 foramen root, which is divided into two branches, caudally afferent to the pole of the superior and inferior lesion. Minor afferents lesion could be appreciated from the trunk ipsilateral cervical thyroid-visible, in wastewater, even during the study right vertebral artery (Figure 4).

Branching out from the artery root right C5 C6 are responsible for the SPINAL vascularization of the neoformation interesting the right portion of the body mass and articular process C5. Widespread and intense opacification of the epidural venous plexus and vertebral perimedullary ipsilateral.

Considering the risk of thermal damage to the spinal cord, nerve roots and vertebral artery using Tc-guided radiofrequency ablation we performed an open approach in order to completely remove the lesion (with excision of the lesion with curettage of the nidus) and control possible vertebral artery injury. We got a complete regression of symptoms in the immediate post-operative period and the patient is asymptomatic 2 year after surgery (Figure 5).

\section{Discussion}

Described by Jaffe in 1935, osteoid osteoma is a small, benign, osteoblastic skeletal neoplasm consisting of a highly vascularised nidus of connective tissue surrounded by sclerotic bone. The nidus is usually less than $15 \mathrm{~mm}$ and when larger is classified as osteoblastoma. Since then have been described in the literature more than 1000 cases [5]. Osteoid osteoma comprises $10 \%$ of all benign bone tumors and only $1 \%$ of all spinal tumors [19]. Jackson reviewed 860 cases of osteoid osteoma and found that $10 \%$ occurred in the spine: $59 \%$ occurred in the lumbar spine, $27 \%$ in the cervical spine, $12 \%$ in the thoracic spine and $2 \%$ in the sacrum. The posterior element was involved in $75 \%$ of cases and only $7 \%$ occurred in the vertebral body.

The location of the lesion at the cervical articular process is very rare and its complete excision involves the risk of spinal cord injury, root and vertebral artery [19]. The differential diagnosis of patients, especially younger patients, with neck pain, painful scoliosis, spine stiffness, radicular pain in the arm, or pain extending toward the shoulder, should include cervical osteoid osteoma and osteoblastoma $[4,14,20,21]$.

Common symptoms with many other diseases might have considerably delayed the diagnosis of these diseases [14].
Additionally, these tumors often cause pain before being visible on $\mathrm{X}$-ray radiographs.

In recent years, however, MRI or CT examinations have often been used to diagnose patients with neck pain; as a result, delays in diagnosis have significantly decreased [14].

Typical clinical symptoms of osteoid osteoma and osteoblastoma localized in the neck are similar. The earliest clinical symptom of osteoid osteoma and osteoblastoma of the neck is continuous local pain in the areas of the lesion, which is particularly evident at night. Observed pain of this character usually responds well to aspirin and other NSAIDS. There might be moderate or severe sensitivity of the tumor tissue [22].

As reported in previous publications, osteoid osteoma and osteoblastoma are usually seen in individuals under the age of 30 . The preferred treatment option for osteoid osteomas and osteoblastomas is the complete removal of the tumor tissue [14].

For osteoid osteoma, total resection including the nidus would ensure immediate pain relief in the postoperative period. Its recurrence rate has been reportedto be as low as $4.5 \%$ [14].

\section{Conclusion}

The osteoid osteoma of the cervical spine should be suspected in any young patient with cervicobrachial or neck pain especially if the pain gets worse at night, gets better after taking salicylates and is accompanied by stiff neck and a rapid onset scoliosis.

Surgical treatment is the definitive treatment and complete excision of the tumor leads to a rapid and permanent improvement of pain symptoms. An early recurrence of pain suggests an incomplete excision of the lesion. Complete surgical excision of the osteoid osteoma through a limited approach is rather difficult: there are numerous published observations that these result in "premature recurrences" due to an incomplete excision of the lesion. In these cases, the natural history of the $\mathrm{OO}$, that can also evolve spontaneously, but unpredictable healing can indicate therapeutic suspension but persisting intense pain can require reintervention.

Frequent localization in the joint-peduncle area can require extensive excision of the $\mathrm{OO}$, with an interruption of the spinal column and arthrodesis, resulting in a limitation of mobility of the spinal column secondary to fusion.
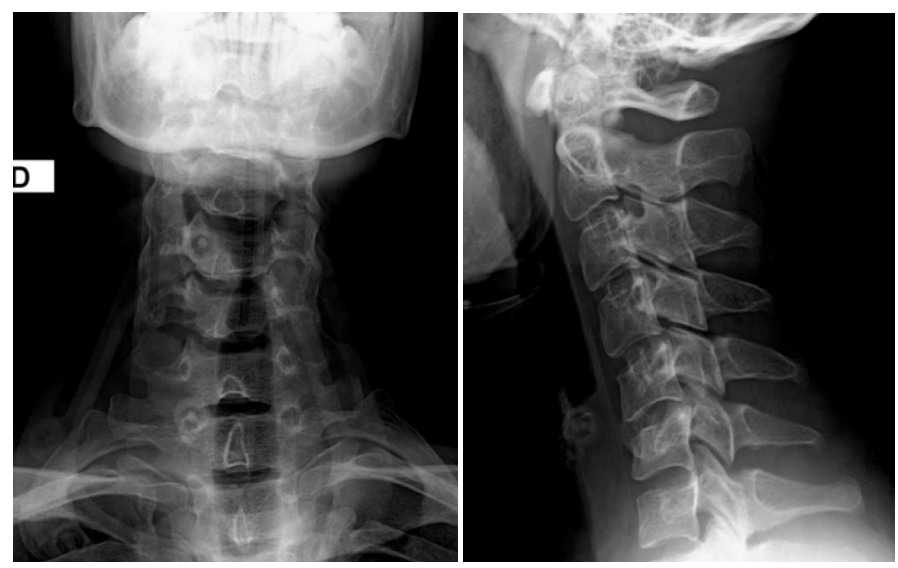

Figure $1(\mathbf{a}, \mathbf{b})$. The X-ray examination showing an expansive lesion at the articular process of sixth cervical vertebra surrounded by sclerosis. The three-phase [Tc-99] MDP bone scan was positive with an increased uptake at the lower cervical region. 

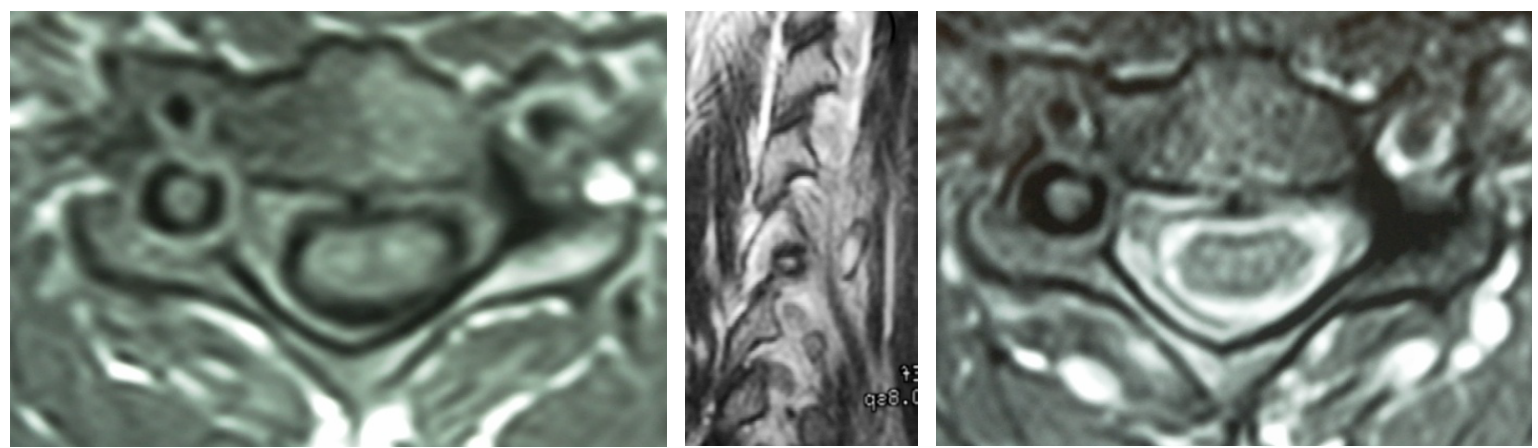

Figure $2(\mathbf{a}, \mathbf{b}, \mathbf{c})$. MRI with T1 weighting showed a diffuse hypointensity signal area in the right joint process of $\mathrm{C} 6$ and a focal high signal area on T2 weighting images
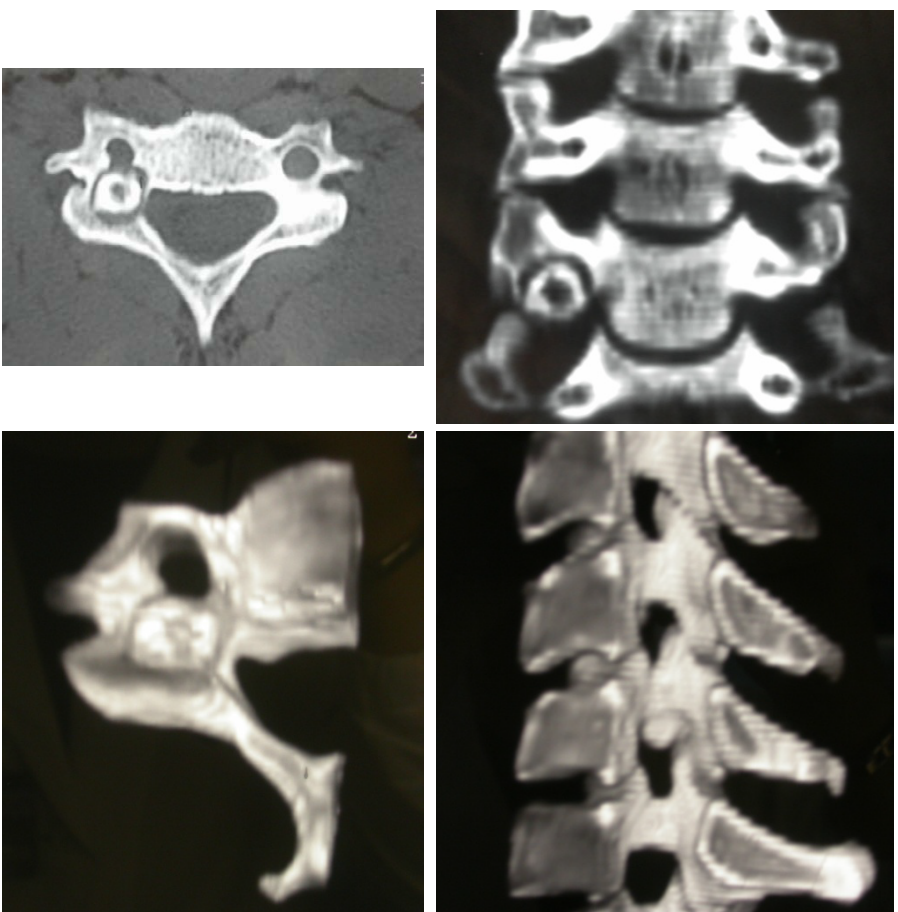

Figure $3(\mathbf{a}, \mathbf{b}, \mathbf{c}, \mathbf{d})$. CT examination showed an oval lesion surrounded by an area of sclerosis on the right articular process of $\mathrm{C} 6$ which formed the medial wall of the right vertebral artery foramen.
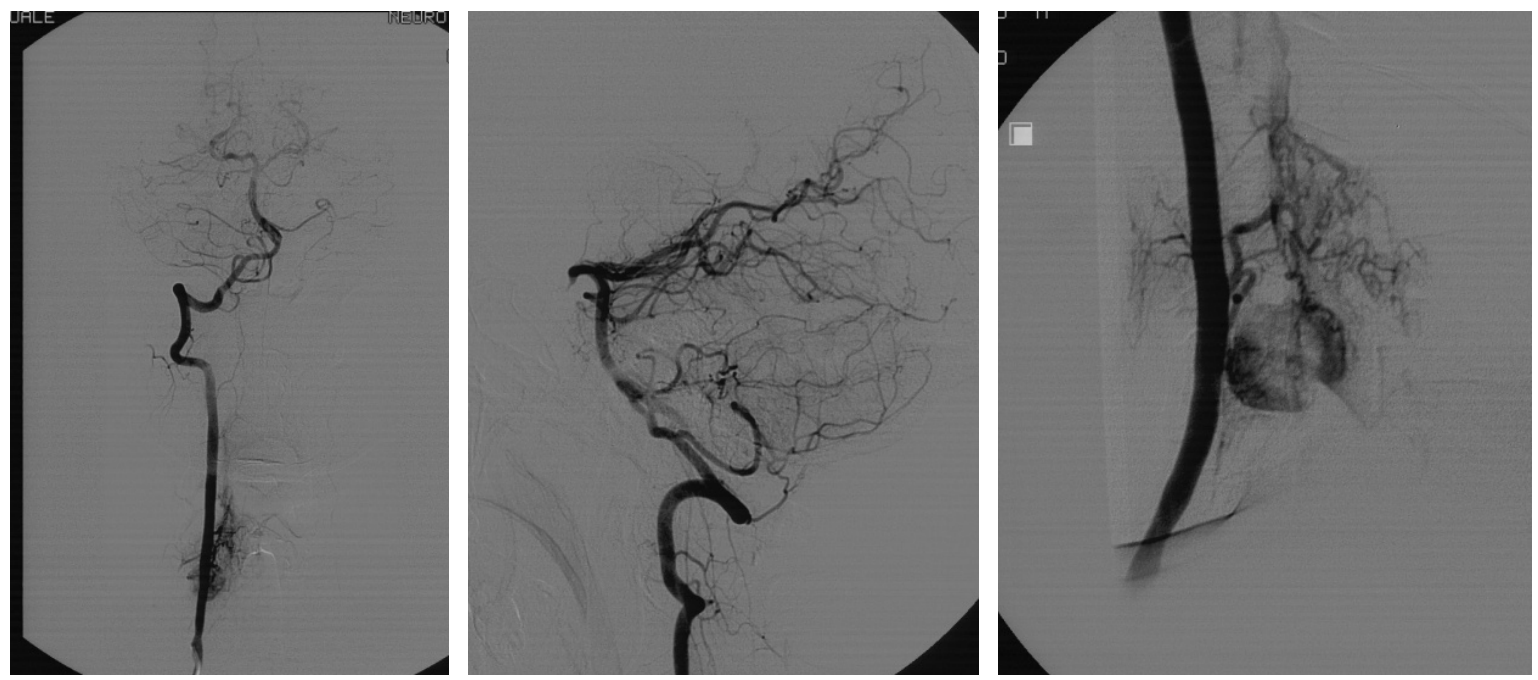

Figure $4(\mathbf{a}, \mathbf{b}, \mathbf{c})$. selective arteriography showed the presence of neoformed vessels with intense and persistent vascular flow of the lesion originated from an ectasic root of the right vertebral artery. 

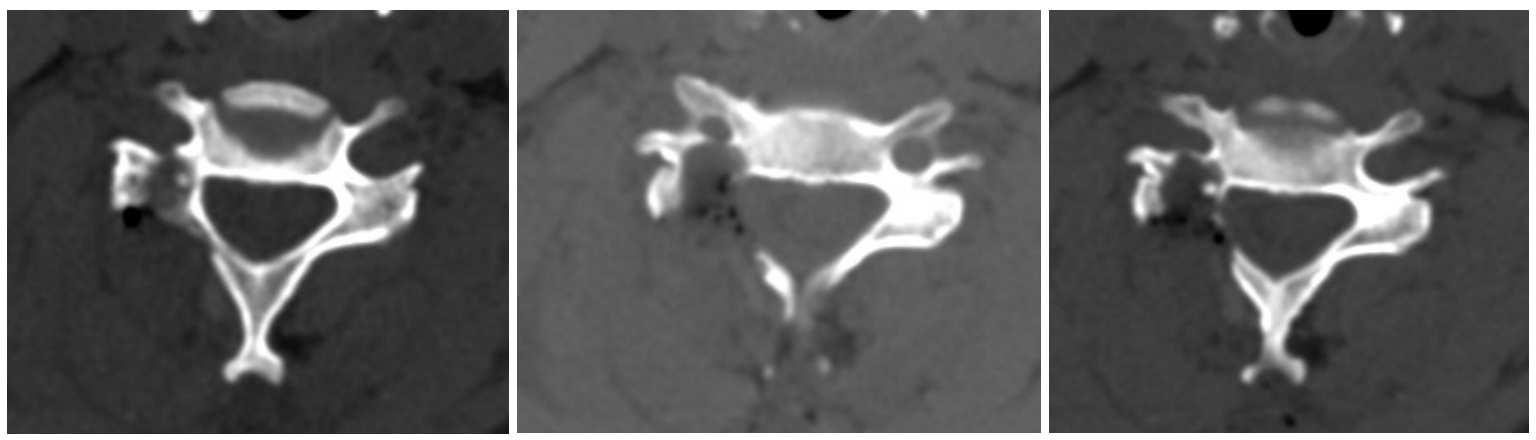

Figure $5(\mathbf{a}, \mathbf{b}, \mathbf{c})$. Complete excition of the lesion with curettage of the nidus.

\section{References}

1. Fielding JW, Keim HA, Hawkins RJ, Gabrielian JC (1977) Osteoid osteoma of the cervical spine. Clin Orthop Relat Res: 163-164. [Crossref]

2. Huvos AG (1979) Bone tumors. Philadelphia, WB Saunders, USA, pp: 33-46.

3. Nemoto O, Moser RP Jr, Van Dam BE, Aoki J, Gilkey FW (1990) Osteoblastoma of the spine. A review of 75 cases. Spine (Phila Pa 1976) 15: 1272-1280. [Crossref]

4. Zileli M, Cagli S, Basdemir G, Ersahin Y (2003) Osteoid osteomas and osteoblastomas of the spine. Neurosurg Focus 15: E5. [Crossref]

5. Jaffe HL (1935) Osteoid osteoma: a benign osteoblastic tumor composed of osteoid and atypical bone. Arch Surg 31: 709-728.

6. Lichtenstein L (1956) Benign osteoblastoma: A category of osteoid and bone forming tumors other than classical osteoid osteoma, which may be mistaken for giant- cell tumor or osteogenic sarcoma. Cancer 9: 1044-1052. [Crossref]

7. Black JA, Levick RK, Sharrard WJ (1979) Osteoid osteoma and benign osteoblastoma in childhood. Arch Dis Child 54: 459-465. [Crossref]

8. Kiers L, Shield LK, Cole WG (1990) Neurological manifestations of osteoid osteoma. Arch Dis Child 65: 851-855. [Crossref]

9. Hurtgen KL, Buehler M, Santolin SM (1996) Osteoid osteoma of the vertebral body with extension across intervertebral disk. J Manipulative Physiol Ther 19: 118-123. [Crossref]

10. Wilner D (1982) Osteoid osteoma. In:Radiology of bone tumors and allied disorders. Philadelphia: WB Sauders Co, USA, pp: 144-216.

11. Dahlin DC (1987) Bone tumors general aspects and data on 8342 cases. Springfield: Thomas, USA, pp: 88-101.

12. Greenspan A (1993) Benign bone forming lesions:osteoma, osteoid osteoma, osteoblastoma. Clinical imaging, pathologic and differential considerations. Skel Radiol 22: 485-500. [Crossref]
13. Laus M, Zappoli FA, Malaguti MC, Alfonso C (1997) Surgery of primary bone tumors close to the vertebral artery. XIII Meeting Cervical Spine Research Society, European Section, Burgenstock Estate, Switzerland 26-28 June 1997, Abstract book, pp: 31.

14. Ozaki T, Liljenqvist U, Hillmann A, Halm H, Lindner N, et al. (2002) Osteoid osteoma and osteoblastoma of the spine: experiences with 22 patients. Clin Orthop Relat Res: 394-402. [Crossref]

15. Barei DP, Moreau G, Scarborough MT, Neel MD (2000) Percutaneous radiofrequency ablation of osteoid osteoma. Clin Orthop Relat Res: 115-124. [Crossref]

16. Ghanem J, Collet LM, Kharrat K, Samaha E, Deramon M, et al. (2003) Percutaneous radiofrequency coagulation of osteoid osteoma in children and adolescents. J Ped Orthop B 12: 244-252. [Crossref]

17. Pinto CH, Taminiau AHM, Vanderschueren GM, Hogendoorn PC, Bloen JL, Obermann WR (2002) Technical consideration in CT-guided radiofrequency thermal ablation of osteoid osteoma: tricks of the trade. AJR Am J Roentgenol 1633: 1642. [Crossref]

18. Laus M, Albisinni U, Alfonso C, Zappoli FA (2007) Osteoid osteoma of the cervical spine: surgical treatment or percutaneous radiofrequency coagulation? Eur Spine J 16: 2078-2082. [Crossref]

19. Jackson RP, Reckling FW, Mank FA (1977) Osteoid osteoma and osteoblastoma: similar histologic lesions with different natural histories. Clin Orthop 128: 303-313. [Crossref]

20. Boriani S, Capanna R, Donati D, Levine A, Picci P, et al. (1992) Osteoblastoma of the spine. Clin Orthop Relat Res: 37-45. [Crossref]

21. Bruneau M, Cornelius JF, George B (2005) Osteoid osteomas and osteoblastomas of the occipitocervical junction. Spine (Phila Pa 1976) 30: E567-571. [Crossref]

22. Pettine KA, Klassen RA (1986) Osteoid-osteoma and osteoblastoma of the spine. $J$ Bone Joint Surg Am 68: 354-361. [Crossref]

Copyright: (C2017 Martiniani M.This is an open-access article distributed under the terms of the Creative Commons Attribution License, which permits unrestricted use, distribution, and reproduction in any medium, provided the original author and source are credited. 